\title{
PSYCHOLOGICAL WELL-BEING AND ITS RELATION TO ACADEMIC PERFORMANCE OF STUDENTS IN GEORGIAN CONTEXT
}

Tamara Turashvili, Marine Japaridze

Ilia State University, Tbilissi, Georgia

E-mail: tamar.turashvili.1@iliauni.edu, gemarine_japaridze@iliauni.edu.ge

\begin{abstract}
Well-being is a dynamic concept that includes subjective, social, and psychological dimensions as well as health-related behaviors. It is often thought of as one of the hallmarks of the liberal arts experience, resulting from educational encounters that both guide students in the search for meaning and direction in life and help them realize their true potential. Research of students' well-being is conducted in various countries, but it is the first study conducted in Georgia. The objectives of the studies were to test hypothesis, that because of social, political and economic conditions, and frequent reforms in educational system of Georgia, the majority of the students have high level of depression, low level of well-being, that is reflected on their academic performance.

Within the framework of the research 252 students from wide variety of disciplines, of mean age 21 were surveyed. The study methods are Ryff well-being inventory which consists of series of statements reflecting the six areas of psychological well-being, combination with Coping Inventory for Stressful Situation (CISS), from Endler \& Parker and, Kucher Adolescent depression scale (KADS-6).The Results of the study show, that majority of students have middle level of well-being, do not have depression and average self-evaluated academic performance. The research also revealed that the students, who have medium or high level of academic performance, have high index of well-being, purpose of life and personal growth on scale. Also, those students who carry task oriented coping strategy, have high index of well-being, and personal growth on the scale. But the students, who carry avoidance coping strategy, have high level of depression.
\end{abstract}

Key words: academic performance, coping, depression, personal growth, purpose of life, student, wellbeing.

\section{Introduction}

The pursuit of happiness or psychological well-being is central to human existence. Therefore, psychological well-being is a popular topic of psychological research. Questions concerning the personal characteristics and contextual factors that predict psychological wellbeing in the student age are central in that line of research.

Georgian students that acquire higher education are considered to be the future leaders. Academic success is regarded as their major life achievement and key goal of life. During their academic career, students face various responsibilities and challenges and this could be the main reason and primary source of their stress and anxiety. In the majority of cases adolescents are able to handle the difficulties which they face; however, in the number of cases these challenges may have a serious impact on the young person's psychological well-being. In order for adolescents to achieve their life goals and obtain academic success, it is important to be in a psychologically healthy condition. Stressful atmosphere may create and/or elevate psychological distress and reduce their academic performance (Dwyer \& Cummings, 2001). 
PROBLEMS

OF EDUCATION

IN THE $21^{\text {st }}$ CENTURY

Volume 49, 2012

volume 49, 2012

Emotional intelligence, self-efficacy, and psychological well-being (happiness, life satisfaction and depression) are important resources for enhancing students' learning, success and quality in education (Salami, 2010).

In the context of bottom-up and top-down models of subjective well-being, three main sources are discussed: socio-structural characteristics, personality traits and self regulatory indicators (e.g., Brief, Butcher, George, \& Link, 1993; Costa et al., 1987; Diener, 1994; Ryff, 1989; Smith, Fleeson, Gleiselmann, Settersten \& Kunzmann, 1999; Staudinger \& Fleeson 1996; Veenhoven,1991). Further lifespan theory argues that socio-structural characteristics as well as psychological characteristics might take on different functions and, therefore, show different effects depending on the larger cultural context in which they are embedded (e.g., P.B.Baltes, Lindenberger, \& Staudinger, 1998).

The research of student well-being can be useful for colleges and universities in understanding the degree to which their students are self-accepting, are pursuing meaningful goals with a sense of purpose in life, have established quality ties with others, are autonomous in thought and action, have the ability to manage complex environments to suit personal needs and values, and continue to grow and develop.

\section{Problem of Research}

Well-being as a multifaceted concept is often thought of as one of the hallmarks of the liberal arts experience, resulting from educational encounters that both guide students in the search for meaning and direction in life and help them realize their true potential.

In Diener, Suh, Lucas, and Smith (1999) review of the area of Subjective well-being the relationship between Education and Psychological well-being (PWB) is discussed. Small, but significant correlation between education and PWB has often been found (e.g., Campbell et al., 1976; Diener et al., 1993). In a meta - analysis of the literature, Witter, Okun, Stock, and Haring (1984) reported a median effect size of .13. Education is more highly related to well-being for individuals with lower incomes (Campbell, 1981; Diener et al., 1993) and in poor countries (Veenhoven, 1994a).

As Diener, Suh, Lucas, and Smith (1999) described, it is plausible that education may have other indirect effects on PWB as well. Education may contribute to PWB by allowing individuals to make progress toward their goals or to adapt to changes in the environment around them. Diener, Sandwick, Seidlitdz, and Diener (1993) found a correlation between income and PWB in a sample in the United States. In Diener, Suh, Lucas, and Smith (1999) review wealthier people are consistently happier, than poorer people.

Most researchers emphasized the importance of having goals. Commitment to a set of goals provides a sense of personal agency and a sense of structure and meaning to daily life. McCrae and Costa (1996) found that certain coping strategies, for example rational action, were perceived as effective coping responses by respondents, and those, who used these forms of coping (Imedadze, N., Ksovrelashvili, L.,2003) reported higher well-being.

\section{Research Focus}

The main purpose of the present study was to identify the degree of psychological wellbeing of students in Georgian context. The study explored which factors are influencing on the students well-being and whether well-being and academic performance were correlated. Students' purpose of life, tendency of personal growth, financial background (job and salary) and coping strategies moderate the influence of life circumstance and events on students psychological well-being. 
Tamara TURASHVILI, Marine JAPARIDZE. Psychological Well-Being and Its Relation to Academic Performance of Students in Georgian Context

\section{General Background of Research}

Teleological theories of well-being have claimed (e.g., Diener, 1984) and empirical evidence has demonstrated that involvement in the pursuit of goals, as well as goal commitment, contributes to subjective well-being (e.g., Emmons, 1996; Omodei \& Wearing, 1990). In Diener, Suh, Lucas, and Smith (1999) review subjective well-being is a broad category of phenomena that includes people's emotional responses, domain satisfactions and global judgment of life satisfaction. Few existing theories attempt to explain why variables differently relate to the separate components of psychological well-being (PWB). Early research on PWB was limited to cataloging the various resources and demographic factors that are correlated with psychological well-being. The most recent 30 years of research have increased our knowledge in this area, the most important contribution is in the understanding that these external, bottom-up factors often are responsible for only a small part of variance in PWB. Temperament and cognitions, goals, culture and adaptation coping efforts moderate influence of life circumstances and events on PWB. In Diener, Suh, Lucas, and Smith (1999) review theoretical models have been developed in each of these areas to explain how internal factors within the person moderate and mediate the impact of the environment on people's PWB. An increasing number of researchers now focus on people's goals and strivings on how people coping with difficulties. There is no simple answer to what causes PWB. Studies of religion, coping and attribution suggest that cognitive factors play an important role. Studies of people with disabilities show that objective factors can matter, but people often adapt their goals to what is possible for them. Studies of heritability demonstrate that personality plays an important role. Cross-cultural studies reveal that different factors correlate with PWB in different societies. Researcher should be open to the possibility that different strategies work better in different environments and different people. They need to understand the complex interplay of culture, personality, cognitions, goals and resources and the objective environment (Diener et.al., 1999)

Psychological well-being (Khramtsova, Sarrnio, Gordeeva, \& Williams, 2007) have been shown to predict students' attitudes and academic performance in higher educational institutions (Salami, 2010). Thus, the overall question of interest of many studies was to discover, how changes in emotional intelligence, self-efficacy and psychological well-being (happiness, life satisfaction and depression) are related to students' behaviors and attitudes. Therefore, positive emotions have a potentially adaptive and interactive nature and might moderate the relationship between stress or depression and college students' behaviors and attitudes that lead to success (Salami, 2010).

\section{Sample of Research}

For this research participants $(n=252$, mean age 21$)$ were chosen out of five national universities of Georgia from a wide variety of disciplines. The respondents were chosen using simple random selection. The students completed the Ryff well-being scale, coping strategy scale (CISS), Kucher Adolescent depression scale (KADS -6) and Scale of academic achievement.

\section{Instrument and Procedures}

The Research instrument was the medium version of a questionnaire, designed to assess six global dimensions of psychological well-being and continued personality growth across the life span (Ryff, 1989). The Ryff is a straightforward and relatively short survey that assesses 
PROBLEMS

OF EDUCATION

IN THE $21^{\text {st }}$ CENTURY

Volume 49, 2012

the psychological component of well-being. Ryff well-being inventory consisting of 54 Items on the 6 point Scale of a series of statements reflecting six areas of psychological well-being: autonomy, environmental mastery, personal growth, positive relations, purpose in life, and self-acceptance. For each category, a high score indicates that the respondent has a mastery of that area in his or her life. Conversely, a low score shows that the respondent struggles to feel comfortable with that particular event. For this research, the items were first adapted in Georgian language, $\mathrm{n}=799$ respondents, $\mathrm{R} 2 A D J=.01, \mathrm{~F}(2,289)=1.65, \mathrm{p}<.05$ (Japaridze, Turashvili \& Kechakmadze, 2011).

Academic performance data were assessed by self-evaluation scale, from 10 to 100 (university notes).

Coping Inventory for Stressful Situation (CISS), is a four-factor model of human coping with adversity developed by Endler and Parker, 1990. Their construct differentiates three types of coping: emotion-oriented, task oriented, and avoidant.

Kucher Adolescent depression scales (KADS-6), is a self-report scale specifically designed for diagnosis and assesses the severity of adolescent depression.

All participants completed the information: age, gender, job and salary, education. Participation was voluntary and anonymous. The questionnaire took about 1 hour to complete.

\section{Data Analysis}

Descriptive and correlation research analysis was used in the current study. To evaluate the factors, T-test and Anova were used which allow to determine if the averages of two or more samples are significantly different and Pearson's correlation was used to determine which factors are influencing each other. Statistics program SPSS 21 was used to process the results.

\section{Results of Research}

While processing the data, subjective and objective factors that impact students' psychological well-being were set out separately. Subjective factors of personal characteristics: personal growth, purpose of life, autonomy, coping strategies and objective factors: academic performance, financial background (job and salary), were reviewed as the predictors of psychological well-being.

\section{Well-being, Academic Performance, and Gender Difference}

The table 1 shows that, average indicator of students $\mathrm{PWB}$ is $\mathrm{M}=37.5(\mathrm{SD}=3.7$; $\mathrm{df}=$ 245). The results shows gender differences in respect to autonomy, where the average indicator of males' level of autonomy is higher than females' $(\mathrm{t}=2.675 ; \mathrm{p}=0.008 ; \mathrm{df}=250)$. Also gender differences are revealed in self-acceptance scale, where female students' average indicator is higher than male students' $(\mathrm{t}=2.334 ; \mathrm{p}=0.02$; $\mathrm{df}=250)$.

The Results shows, there are no gender differences in respect to average academic performance $(M=70,8, S D=13,0)$. Table 2 shows, that female and male students who evaluate their academic performance as medium or high, have a higher level of personal growth $(\mathrm{F}=6,87$; $\mathrm{p}=0.001 ; \mathrm{df}=2)$, the purpose of life $(\mathrm{F}=14.4 ; \mathrm{p}=0.000 ; \mathrm{df}=2)$ and well-being $(\mathrm{F}=0.08 ; \mathrm{p}=0.004$; $\mathrm{df}=2$ ), than the students who have academic performance lower than average. 
Tamara TURASHVILI, Marine JAPARIDZE. Psychological Well-Being and Its Relation to Academic Performance of Students in Georgian Context

Table 1. Well-being, gender difference.

\begin{tabular}{|c|c|c|c|c|c|c|c|}
\hline Variables & Gender & Mean & SD & F & t & df & p \\
\hline \multirow{2}{*}{ Well-being } & Female & 37.5 & 3.6 & 0.34 & 0.09 & 245 & 0.93 \\
\cline { 2 - 8 } & Male & 37.5 & 4 & & & & \\
\hline \multirow{2}{*}{ Autonomy } & Female & 36 & 7.2 & 0.35 & -2.7 & 250 & 0.008 \\
\cline { 2 - 8 } & Male & 38.8 & 7.6 & & & & \\
\hline \multirow{2}{*}{ Self - acceptance } & Female & 34.3 & 5.1 & 0.3 & 2.3 & 250 & 0.02 \\
\cline { 2 - 9 } & Male & 32.6 & 4.6 & & & & \\
\hline
\end{tabular}

Independent Samples $\mathrm{T}$ test $*$ significant at the $\mathrm{p}<0.05$ level

Table 2. Low and high academic performance, mean difference.

\begin{tabular}{|c|c|c|c|c|}
\hline $\begin{array}{c}\text { Subjective } \\
\text { variables }\end{array}$ & Academic performance & df & F & p \\
\hline Personal growth & low & 2 & 6.9 & 0.001 \\
\hline Purpose of life & high & & & \\
\hline & low & 2 & 14.4 & 0.000 \\
\hline Well-being & high & & & \\
\hline & low & 2 & 5.7 & 0.004 \\
\hline
\end{tabular}

Independent Samples T test, $*$ significant at the $\mathrm{p}<0.05$ level

\section{Coping Strategies, Gender Difference}

Most of the students use task oriented coping (53\%) and emotion oriented coping (35\%) strategy. Table 3 shows that male students have higher level of avoidance coping $(\mathrm{t}=2.374 ; \mathrm{p}=0$. $02 ; \mathrm{df}=249)$, than female students. No differences are revealed in using other coping strategies in respect to gender.

Students with job and salary have higher indicators on the scale of well-being $(\mathrm{t}=2.352$; $\mathrm{p}=0.019 ; \mathrm{df}=245)$ and environmental mastery $(\mathrm{t}=2.725 ; \mathrm{p}=0.007 ; \mathrm{df}=250)$, than the students who do not have own income.

Table 3. Coping strategies, gender difference.

\begin{tabular}{|c|c|c|c|c|c|c|c|}
\hline Coping strategies & Gender & Mean & SD & $\mathbf{F}$ & $\mathbf{t}$ & $\mathbf{d f}$ & $\mathbf{p}$ \\
\hline \multirow{2}{*}{ Task Oriented Coping } & Female & 15.7 & 1.9 & 3.3 & -1.3 & 249 & 0.18 \\
\cline { 2 - 8 } & Male & 16.1 & 2.2 & & & & \\
\hline \multirow{2}{*}{ Emotion Oriented Coping } & Female & 12.4 & 3 & 1.8 & 0.2 & 249 & 0.85 \\
\cline { 2 - 8 } & Male & 12.3 & 3.3 & & & & \\
\hline \multirow{2}{*}{ Avoidance Oriented Coping } & Female & 19.8 & 3.3 & 5.9 & $-2.4^{*}$ & 249 & 0.02 \\
\cline { 2 - 8 } & Male & 21.1 & 4.9 & & & & \\
\hline
\end{tabular}

Independent Samples $\mathrm{T}$ test, *significant at the $\mathrm{p}<0.05$ level 
PROBLEMS

OF EDUCATION

IN THE $21^{\text {st }}$ CENTURY

Volume 49, 2012

78

Depression, Coping, and Psychological Well-being

The research revealed that on depression scale students have lower than average indicator $(\mathrm{M}=13,26 ; \mathrm{SD}=4,1 ; \mathrm{df}=250)$, which means that the majority of the students do not suffer from depression. At the same time, those students who do not have depression, have high indicators on scales of task oriented coping $(\mathrm{t}=3.925 ; \mathrm{p}=0.000 ; \mathrm{df}=249)$ and emotional coping $(\mathrm{t}=4.609$; $\mathrm{p}=0.000 ; \mathrm{df}=249$ ).

Those students who use task oriented coping strategy, have high indicators on the scale of PWB ( $\mathrm{t}=4.239 ; \mathrm{p}=0.000 ; \mathrm{df}=244)$ and low indicators on depression scale $(\mathrm{t}=4.04 ; \mathrm{p}=0.000$; $\mathrm{df}=249)$, unlike the students, who do not use this strategy.

Those students, who use task oriented coping strategy also have high indicators on the scales of personal growth $(\mathrm{t}=4.016 ; \mathrm{p}=0.000 ; \mathrm{df}=249)$, autonomy $(\mathrm{t}=3.970 ; \mathrm{p}=0.000 ; \mathrm{df}=249)$, unlike the students, who do not use this strategy.

Those students, who use evidence coping strategy have high indicators on the scale of depression $(\mathrm{t}=3.491 ; \mathrm{p}=0.001 ; \mathrm{df}=249)$. But, usage of this strategy does not influence indicators of PWB.

Survey results show that there are specific objective and subjective factors, which may have a positive impact on students' psychological well-being - or just become predictors of depression.

\section{Discussion}

The main aim of this study was to identify the degree of well-being of students in Georgian context, and investigate the relationship of psychological well-being (purpose of life, personal growth, depression) and coping strategies with students' academic performance.

It was found, that the hypothesis, that Georgian students would have high levels of depression and low level of well-being and academic performance, because of social, political and economic conditions in Georgia in late years, was not confirmed.

At the same time, continuous and inconsistent reforms in the educational system of Georgia in late years, serve as the reason of stress for all the connected individuals.

Most of the families of students, due to the social situation in Georgia, have very low income and pay high tuition fee for education. State grant finances very small percentage of total fee, and is not available for all students.

Despite of existing environmental factors, which serve as sources of stress for students, our hypothesis was not proved. The majority of students does not have depression and have upper than the average index of well-being. Academic performance index is also more than average on self acceptance scale. It seems, students see difficulties in environment as a challenge, and it is not perceived as a problem by them. Also, purpose of life and the trend of personal growth and development helps them to overcome daily difficulties. Commitment to a set of goals provides a sense of personal urgency and a sense of structure and meaning to daily life. Certain coping strategies, such as rational action, were perceived as effective coping responses by respondents (McCrae \& Costa, 1996) and students using task oriented coping strategies reported higher well-being 0.26 . Theoretical background of this study is based on positive psychology theory by Seligman (2008), which states that happiness, promotes success across various arenas of human functioning. Therefore, coping strategies, sense of directedness, importance of present and past life (purpose of life), feeling of continued development, open to new experience, realizing his or her potential, changing ways that reflect more self knowledge and effectiveness (personal growth).

Correlation was revealed between students' academic performance and well-being 0.23 (Diener et.al., 1999) Education contributes to PWB by allowing individuals to make progress 
Tamara TURASHVILI, Marine JAPARIDZE. Psychological Well-Being and Its Relation to Academic Performance of Students in Georgian Context

toward their goals or to adapt to changes in the world around them. Research revealed a

correlation between income and PWB (Diener et.al., 1999).

For global finding is an absence of mean differences between males and females (e.g., Levkoff et al., 1987; Mayers \& Diener, 1995). Gender differences were not confirmed in our research, males as well as females have the same average marker on PWB scale.

The results can aid colleges and universities in understanding the degree to which their students are self-accepting, are pursuing meaningful goals with a sense of purpose in life, have established quality ties with others, are autonomous in thought and action, have the ability to manage complex environments to suit personal needs and values, and continue to grow and develop (Ryff, 1989).

\section{Conclusions}

A questionnaire that measures Psychological Well-Being - Riff Inventory Psychological Well-Being was adapted according to Georgian population. It was established that Georgian students acquire medium level psychological well-being and low level of depression. Subjective and objective factors that effect students' psychological well-being were revealed. From subjective factors having a purpose of life, orientation on personal growth and having certain coping strategies turned out to be the most important. From objective factors, academic Performance and financial background (job and salary) were important. The authors recommend for the teachers and parents to keep in mind the meaning and importance of the factors that influence students' psychological well-being to better understand and evaluate students' personal needs and values, in order to assist and help them through their personal growth and development.

The major goal of future research will be to clarify the inter correlation between external and internal factors moderate and mediate the impact of the environment on students' psychological well-being.

\section{References}

Brief, A. P., Butcher, A. H., George, J. M., \& Link, K. E. (1993). Integrating bottom up and top down theories of subjective well-being: The case of health. Journal of personality and Social Psychology, 64, 646-653.

Brooks, S. J., \& Kutcher, S. (2001). Diagnosis and measurement of adolescent depression: A review of commonly utilized instruments. Journal of Child and Adolescent Psychopharmacology, 11, 341-376.

Campbell, A. (1981). The sense of well-being in America: Resent patterns and trends. New York: McGrow-Hill.

Campbell, A., Converse, P. E., \& Rodgers, W. L. (1976). The quality of American life. New York: Russell Sage Foundation.

Costa, P. T., McCrae, R. R., \& Zonderman, A. B. (1987). Environmental and dispositional influences on well-being: Longitudinal follow-up of an American national Sample. British Journal of Psychology, 78, 299-306.

Diener, E. (1994). Assessing subjective well-being: Progress and opportunities. Social Indicators Research, 31, 103-157.

Diener, E., Sandvik, E., Seidlitz, L., \& Diener, M. (1993). The relationship between income and subjective well-being: Relative or absolute? Social indicators Research, 28, 195-223.

Diener, E., Suh, M., Lucas E., \& Smith L. (1999). Subjective well-being: Three decades of progress. American psychological association, psychological bulletin, 125, 276-302.

Dwyer, A. L. \& Cummings, A. L. (2001). Stress, self-efficacy, social support and coping strategies in University Students. Canadian Journal of Counselling, 35, 208-220.

Endler, N. S., \& Parker, J. D. A. (1990). Coping Inventory for Stressful Situations (CISS). Toronto: MultiHealth Systems, Inc. 
PROBLEMS

OF EDUCATION

IN THE $21^{\text {st }}$ CENTURY

Volume 49, 2012

Japaridze, M., Turashvili, T., \& Kechakmadze, I. (2011). Ryff well-being inventory. Adopted on Georgian population. Unpublished manuscript.

Imedadze, N., \& Ksovrelashvili, L. (2003). Study of coping strategies in Georgian adolescents. In Stress and coping strategies. Symposium conducted at the XI. European Conference on Developmental Psychology, Milan, Italy.

Ksovrelashvili, L., \& Imedadze, N. (2004). Adolescent mental health: the case of Georgian students. In Internalizing and externalizing problems and their co-occurrence in adolescents from six different cultural contexts. Symposium at the IX Conference of the European Association for Research on Adolescence EARA, Porto, Portugal.

Ksovrelashvili, L., Flammer, A., Alsaker, F., Nägele, C., \& Imedadze, N. (2004). Well-Being and some cultural and family concerning aspects (Tech. Rep. No. 1). Switzerland: University of Bern, Chair of Developmental Psychology.

Khramtsova, I., Sarrino, D. A., Gordeeva, T., \& Williams. (2007). Happiness, life satisfaction and depression in college students: Relations with student behaviours and attitudes. American Journal of Psychological Research, 3, 8-16.

Levkoff, S. E., Cleary, P. D., \& Wetle, T. (1987). Differences in the appraisal of health between aged and middle-aged adults. Journal of Gerontology, 42, 114-120.

McCrae, R. R., \& Costa, P. T. (1986). Personality, Coping, and Coping effectiveness in adult sample. Journal of Personality, 54, 385-405.

Myers, D. G., \& Diener, E. (1995). Who is happy? Psychological Science, 6, 10-19.

Ryff, C. D. (1989). Happiness is everything, or is it? Explorations on the meaning of psychological wellbeing. Journal of Personality and Social Psychology, 57, 1069-1081.

Salami O. S. (2010). Emotional intelligence, self-efficacy, psychological well-being and students attitudes: implications for quality education. European Journal of Educational Studies, 2, 247-257

Smith, J., Fleeson, W., Geiselmann, B., Settersten, R., \& Kunzmann, U. (1999). Well-being in very old age: Predictions from objective life conditions and subjective experience. In P. B. Baltes \& K. U. Mayer (Eds.), The Berlin Aging Study: Aging from 70 to 100 (pp. 450-471). New York: Cambridge University Press.

Staudinger, U. M., \& Fleeson, W. (1996). Self and personality in old and very old age: A sample case of resilience? Development and Psychopathology, 8, 867-885.

Staudinger, U. M., \& Fleeson, W. (1999). Predictors of Subjective Physical Health and Global Weil-Being: Similarities and Differences Between the United States and Germany. Journal of Personality and Social Psychology, 76, 305-319.

Veenhoven, R. (1991). Questions on happiness: Classical topics, modern answers, blind spots. In F. Strack, M. Argyle, \& N. Schwarz (Eds.), Subjective well-being: An interdisciplinary perspective (pp. 7-25). Oxford, England: Pergamon Press.

Veenhoven, R. (1994a). Correlates of Happiness: 7,836 findings from 603 studies in 69 nations: 19111994. Unpublished manuscript, Erasmus University, Rotterdam, The Netherlands.

Witter, R. A., Okun, M. A., Stock, W. A., \& Haring, M. J. (1984). Education and subjective well-being: A meta analyses. Educational Evaluation and Policy Analysis, 6, 165-173.

Advised by Natela Imedadze, Ilia State University, Tbilisi, Georgia

Received: October 04, 2012

Accepted: November 21, 2012

Tamara Turashvili

Researcher, Ph.D Student, llia State University, 3/5 Cholokashvili Ave.,

Tbilisi, Georgia.

E-mail: tamar.turashvili.1@iliauni.edu.ge

Website: http://www.iliauni.edu.ge

Marine Japaridze

Associate Professor, Ilia State University, 3/5 Cholokashvili Ave.,Tbilisi,

Georgia.

E-mail: marine_japaridze@iliauni.edu.ge

Website: http://www.liliauni.edu.ge 